\title{
THE EFFECT OF MAGNETIC FIELD ON THE EFFICIENCY OF A SILICON SOLAR CELL UNDER AN INTENSE LIGHT CONCENTRATION
}

\author{
Martial Zoungrana ', Issa Zerbo', Boubacar Soro', Mahamadi Savadogo', \\ Sanna Tiedrebeogo ${ }^{1}$, Dieudonné Joseph Bathiebo' ${ }^{1}$ \\ 1 Laboratory of Thermal and Renewable Energies, Department of Physics, Unit of Training and Research in Pure and \\ Applied Sciences, University of Ouagadougou Joseph KI-ZERBO, Burkina Faso, e-mail: zmartial2003@yahoo.fr
}

Received: 2017.03.09

Accepted: 2017.04.22

Published: 2017.06.01

\begin{abstract}
This work put in evidence, magnetic field effect the electrical parameters of a silicon solar cell illuminated by an intense light concentration: external load electric power, conversion efficiency, fill factor, external optimal charge load. Due to the high photogeneration of a carrier in intense light illumination mode, in addition of magnetic field, we took into account the carrier gradient electric field in the base of the solar cell. Taking into account this electric field and the applied magnetic field in our model led to new analytical expressions of the continuity equation, the photocurrent and the photovoltage. In this work, we used the electric power curves versus junction dynamic velocity $\left(S_{j}\right)$ to determine, according to magnetic field, the maximum electric power $\mathrm{P}_{\text {elmax }}$ and we calculate the solar cell conversion efficiency $(\eta)$. We also used the $\mathrm{J}-\mathrm{V}$ characteristics to determine the solar cell short circuit density current $\left(\mathrm{J}_{\mathrm{cc}}\right)$ and the open circuit voltage $\left(\mathrm{V}_{\mathrm{co}}\right)$ under magnetic field and we calculate the fill factor $(\mathrm{FF})$. Finally, we used simultaneously the J-V characteristics and equipower curves to determine the optimal external load resistance. The results of this study have showed that the maximum electric power and the conversion efficiency are higher than those of monofacial and bifacial silicon solar cells illuminated by conventional light but they decreased with the increase of magnetic field.
\end{abstract}

Keywords: conversion efficiency, electric power, fill factor, light concentration, magnetic field, optimal charge load.

\section{INTRODUCTION}

Many authors proposed experimental methods and modelling to study external magnetic field's effect on solar cells properties: InP/ GaInAs heterojunction bipolar transistor [1], $\mathrm{CdS} / \mathrm{CuInSe}{ }_{2}$ photovoltaic cell [2], bifacial solar cells $[3,4]$ and light concentration bifacial silicon solar cell $[5,6]$.

It was proved in previous studies [5] that the values of external magnetic field higher than $7.10^{-5}$ Tesla do not have an influence on solar cell electronic parameters, such as diffusion coefficient, diffusion length and carrier's density.
Also, in the order to define the influence of magnetic field on solar cells, some authors [7] proved that the magnetic field resulting of electromagnetic waves produced by AM and FM radio antennas is very weak to have an influence on the solar cells behavior. But the resulting electric field highly influences the solar cell electronic parameters.

The effect of electric and magnetic fields on the operation of three different types of solar cells (i.e. mono, poly, and amorphous Si solar cells) irradiated by spontaneous light emitting flux was studied by Erel [8]. The experience showed that, taking into account magnetic field led to the reduction of the solar cell 
short circuit current $I_{s c}$ and open circuit voltage $V_{c o}$. This result is contrary to usual ones where the open circuit voltage increases with magnetic field increase $[9,10]$. This situation may be the fact that the solar cell was illuminated by a light emitting diode. The effect of magnetic field and doping density on $\mathrm{J}-\mathrm{V}$ characteristics, shunt and series resistances have been also studied by Sané et al. [11] under a monochromatic frequency modulated light. The study proved that for all doping level, the magnetic field increase led to series resistance, shunt resistance and short circuit current increase.

Since some electrical parameters, such as maximum electric power, conversion efficiency, fill factor and optimal load resistance are directly linked to charge carriers mobility in the base of a solar cell, therefore, a magnetic field can influence these electrical parameters. In previous works $[9,10]$, these electrical parameters have been determined for a bifacial silicon solar cell using the electric power versus junction dynamic velocity and using simultaneously the $\mathrm{J}-\mathrm{V}$ and $\mathrm{P}-\mathrm{V}$ characteristics.

In this work we studied the effect of external magnetic on the electrical parameters of intense light concentration silicon solar cell using the electric power curves versus junction dynamic and using simultaneously the J-V characteristics and equipower curves.

\section{MODEL AND ASSUMPTIONS}

\section{Analytical formulation}

We considered a silicon solar cell operating under a concentrated multispectral light. The cell was excited uniformly on the emitter surface by an intense light concentration (more than

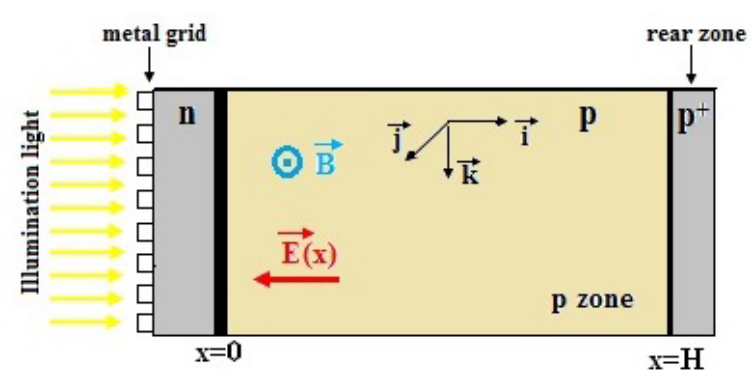

Fig. 1. Intense light illuminated silicon solar cell under magnetic field
50 suns). The light penetrates the junction at the plane $\mathrm{z}=0$ and the back surface was situated at $\mathrm{z}=\mathrm{H}$. Because of the light intensity, carrier concentration in the base was not uniform. So, we took into account the electric field $\mathrm{E}(\mathrm{z})$ due to the difference of carrier concentration on $z$ axis [12].

To investigate the magnetic field influence on electric parameters, we applied a variable external magnetic field with the induction, parallel to the surface of the n-p junction, as shown in Figure 1.

Taking into account the influence of the magnetic field $\bar{B}=\bar{B}_{j}$ and the electric field due to carrier gradient concentration electric field $\bar{E}=-E(x)$ $\bar{l}$ (in intense light concentration mode), the expression of photocurrent density in solar cell base $\bar{J}_{n}$ was given by the equation of transportation phenomenon in Equation $1[1,5]$.

$$
\vec{j}_{n}=e D_{n} \vec{\nabla} \delta-\mu_{n} \vec{j}_{n} \times \vec{B}+e \mu_{n} \delta \vec{E}
$$

The expression of the electric field of carrier concentration gradient is given by Equation 2 [12].

$$
E(x)=\frac{D_{p}-D_{n}}{\mu_{p}+\mu_{n}} \cdot \frac{1}{\delta(x)} \frac{\partial \delta(x)}{\partial x}
$$

In these expressions: $D_{n}$ and $D_{p}$ are respectively electrons and holes diffusion coefficients, $\mu_{\mathrm{n}}$ and $\mu_{\mathrm{p}}$ are electrons and holes mobility, $e$ is the elementary charge and $\delta(x)$ is the excess minority carrier density in the base of the illuminated solar cell.

\section{Determination and resolution of continuity equation}

The resolution of Equation 1 taking into account the expression of electric field due to the carrier concentration gradient, given by Equation 2 , led to the electron photocurrent density expression along the $\mathrm{x}$ axis:

$$
j_{n x}=e\left[\frac{D_{n} \mu_{p}-D_{p} \mu_{n}+2 D_{n} \mu_{n}}{\left[1+\left(\mu_{n} \cdot B\right)^{2}\right]\left(\mu_{n}+\mu_{p}\right)}\right] \frac{\partial \delta(x)}{\partial x}
$$

This expression is simplified as:

$$
\begin{gathered}
j_{n x}=e D_{n p}^{*} \frac{\partial \delta(x)}{\partial x} \\
D_{n p}^{*}=\frac{D_{n} \mu_{p}-D_{p} \mu_{n}+2 D_{n} \mu_{n}}{\left[1+\left(\mu_{n} \cdot B\right)^{2}\right]\left(\mu_{n}+\mu_{p}\right)}
\end{gathered}
$$


$D^{*}{ }_{n p}$ is the new expression of diffusion coefficient of the solar cell submitted to a magnetic field and an intense light concentration.

The general expression of the distribution of excess minority carriers distribution in the solar cell's base along the $\mathrm{x}$ axis is given by:

$$
\frac{\partial \delta(x)}{\partial t}=\frac{1}{e} \frac{\partial j_{n x}}{\partial x}+G(x)-\frac{\delta(x)}{\tau_{n}}
$$

In steady state, Equation 4 becomes Equation 5:

$$
\frac{\partial^{2} \delta(x)}{\partial x^{2}}-\frac{\delta(x)}{L^{*}{ }_{n p}^{2}}+\frac{G(x)}{D^{*}{ }_{n p}}=0
$$

$\mathrm{L}^{*}{ }_{n p}$ is the new expression of diffusion lenght of the solar cell submited to a magnetic field and an intense light concentration.

$G(x)$ is the excess minority carrier generation at depth $x$ in the base of the solar cell and its expression is written as:

$$
G(x)=C \cdot \sum_{i=1}^{3} a_{i} \cdot e^{-b_{i} x}
$$

Coefficients $a_{i}$ and $b_{i}$ are deduced from modelling the generation rate considered for over all the solar radiation spectrum [13] and $\mathrm{C}$ is the light concentration in suns.

The solution of Equation 5 is:

$$
\begin{gathered}
\delta(x, S f, B)=A_{1} \cosh (\alpha x)+ \\
+A_{2} \sinh (\alpha x)+\sum_{i=1}^{3} K_{i} e^{-b_{i} x} \\
\text { with } \\
\alpha=\frac{1}{L_{n p}^{*}} \\
K_{i}=\frac{\text { and } \cdot a_{i}}{D_{n p}^{*} \cdot\left(L_{n p}^{*}{ }^{2}-b_{i}^{2}\right)}
\end{gathered}
$$

The expressions of the coefficients $\mathrm{A}_{1}$ and $\mathrm{A}_{2}$ are obtained by solving Equation 7, with the boundary conditions at the two edges of the base region $[4,5]$ :

- the junction interface at $\mathrm{x}=0$ :

$$
D_{n p}^{*}\left[\frac{\partial \delta(x)}{\partial x}\right]_{x=0}=S f \delta(x=0)
$$

- the rear side at $\mathrm{x}=\mathrm{H}$ :

$$
D_{n p}^{*}\left[\frac{\partial \delta(x)}{\partial x}\right]_{x=H}=-S_{b} \delta(x=H)
$$

In these expressions, $S f$ is the junction dynamic velocity and $S_{b}$ is the back surface recombination velocity.

\section{Expression of photocurrent density and photovoltage}

- Photocurrent density

Photocurrent density expression is given by Equation $(10)[14,15]$ :

$$
\left.J p h(S f, B)=q \cdot D_{n p}^{*} \cdot \frac{\partial \delta(x, S f, B)}{\partial x}\right)_{x=0}
$$

- Photovoltage

The photovoltage is expressed by Boltzmann law $[14,15]$ :

$$
V_{p h}(S f, B)=V_{T} \cdot \ln \left[1+\frac{\delta(x=0, S f, B)}{n_{0}}\right]
$$

In this expression, $V_{T}$ is the thermal voltage given by: $V_{T}=k_{B} \cdot T / q, n_{o}$ expresses the carrier concentration at thermodynamic equilibrium: $n_{o}=n_{i}^{2} / N_{B}, n_{i}$ represents the intrinsic carrier concentration $\left(\mathrm{n}_{\mathrm{i}}=10^{10} \mathrm{~cm}^{-3}\right.$ for silicon $), N_{B}$ is the base doping density $\left(\mathrm{N}_{\mathrm{B}}=10^{16} \mathrm{~cm}^{-3}\right)$ and $k_{B}$ is the Boltzmann's constant.

\section{RESULTS AND DISCUSSION}

\section{Effect of magnetic field on the external load's electric power}

In Equations 10 and 11 photocurrent and photovoltage are functions of magnetic field and junction dynamic velocity (Sf). The solar cell studied in this article is an ideal solar cell so the losses of carriers at the junction interface are neglected and then, the intrinsic junction recombination velocity $\left(S f_{\emptyset}\right)$ is null. The junction dynamic velocity $(S f)$ is assumed equal to the one imposed by an external load resistance $\left(S_{j}\right)$, and then all the carriers collected at the solar cell's junction cross this junction [9].

The electric power provided to an external load resistance is a function of junction dynamic velocity $S_{j}$ and is expressed as:

$$
P_{e l}\left(S_{j}\right)=V_{p h}\left(S_{j}\right) \cdot J_{p h}\left(S_{j}\right)
$$

As photocurrent and photovoltage are functions of magnetic field, therefore, the electric power provided to an external load resistance is also a function of magnetic field. 


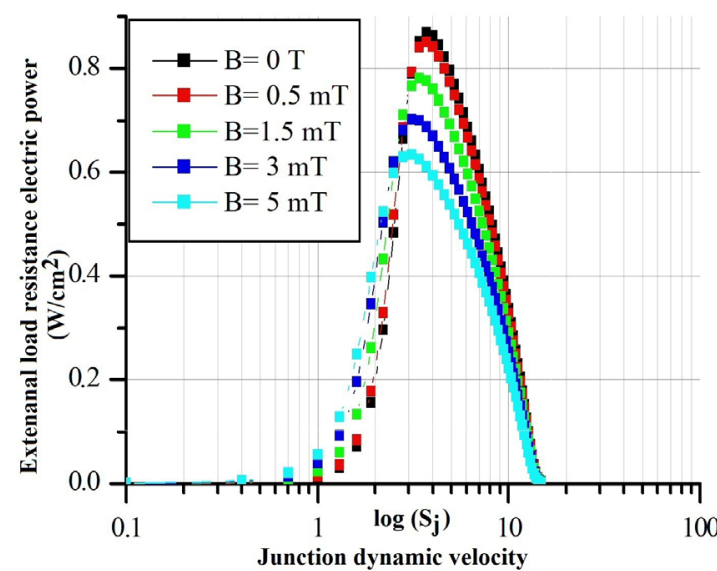

Fig. 2. Effects of junction dynamic velocity and magnetic field on an intense light concentration solar cell

$(\mathrm{C}=50$ suns $)$ external load's electric power

The curves in Figure 2 show junction dynamic velocity and magnetic field effects on the electric power delivered by the solar cell to an external load resistance.

Curves in Figure 2 had the same shapes than those of a previous work [9]. For a given junction dynamic velocity and a given magnetic field intensity, the maximum electric power delivered by the light concentration silicon solar cell is higher than the one produced by a bifacial silicon solar cell. The maximum electric power decreases and it moves towards small values of junction dynamic velocity with magnetic field increase. This situation means that taking into account magnetic field reduces the quantity of carriers which cross the junction to participate to the photocurrent.

\section{Effect of magnetic field on the solar cell's conversion efficiency}

The expression of the solar cell's conversion efficiency is given by the Equation 13 [9].

$$
\eta=\frac{P_{\text {elmax }}}{P_{\text {inc }}}
$$

In this expression, $P_{i n c}$ is the power of the incident light's flux. For a light concentration solar cell and under Air Mass 1,5 standard conditions $\left(1000 \mathrm{~W} / \mathrm{m}^{2}\right)$, the proportion of light, which is concentrated, is around $720 \mathrm{~W} / \mathrm{m}^{2}$ [16]. Thus, for a 50 suns light concentration, $P_{\text {inc }}$ is assumed to be: $P_{\text {inc }}=0.072 \mathrm{~W} / \mathrm{cm}^{2} \cdot 50=3.6 \mathrm{~W} / \mathrm{cm}^{2}$.

In Table 1 we presented the values of external load's maximum electric power and conversion efficiency of intense light concentration solar cell under magnetic field effect.

These results showed that the solar cell external load maximum electric power and its conversion efficiency decrease with the increase of external magnetic field, as shown in a previous work [9]. But the maximum electric power delivered by the light concentration silicon solar cell and its conversion efficiency are higher than those of a bifacial silicon solar cell. As the maximum electric power delivered by the solar cell to an external load is a function of solar cell's photocurrent density and photovoltage, we can deduced that the external magnetic field had an influence on the photocurrent and the photovoltage.

\section{Effect of magnetic field on the solar cell's fill factor}

The solar cell's fill factor is a function of the maximum electric power, the short circuit current density, the open circuit voltage and its expression is given by Equation 14:

$$
F F=\frac{P_{e l \max }}{V_{o c} \cdot J_{s c}}
$$

The short circuit photocurrent density $J_{s c}$ and the open circuit photovoltage $V_{o c}$ are determined using $\mathrm{J}-\mathrm{V}$ characteristics according to magnetic field intensity [10].

Table 1. Magnetic field effect on maximum electric power and conversion efficiency

\begin{tabular}{|l|c|c|c|c|c|}
\hline Magnetic field intensity B $(\mathrm{mT})$ & 0 & 0.5 & 1.5 & 3 & 5 \\
\hline Maximum electric $\mathrm{P}_{\text {el } \max }\left(\mathrm{mW} / \mathrm{cm}^{2}\right)$ & 870 & 851 & 781 & 703 & 635 \\
\hline Conversion efficiency $\eta(\%)$ & 24.167 & 23.639 & 21.694 & 19.528 & 17.639 \\
\hline
\end{tabular}

Table 2. Magnetic field effect on short circuit current, open circuit voltage and fill factor

\begin{tabular}{|l|c|c|c|c|c|}
\hline Magnetic field intensity B $(\mathrm{mT})$ & 0 & 0.5 & 1.5 & 3 & 5 \\
\hline Maximum electric $\left(\mathrm{mW} / \mathrm{cm}^{2}\right)$ & 870 & 851 & 781 & 703 & 635 \\
\hline Open circuit voltage $\mathrm{V}_{\mathrm{co}}(\mathrm{mV})$ & 717 & 721 & 734 & 737 & 756 \\
\hline Short circuit current $\mathrm{J}_{\mathrm{cC}}\left(\mathrm{mA} / \mathrm{cm}^{2}\right)$ & 1431 & 1392 & 1251 & 1104 & 952 \\
\hline Fill factor FF & 0.84793 & 0.84795 & 0.851 & 0.864 & 0.882 \\
\hline
\end{tabular}


In Table 2 we summarized the values of the fill factor, the short circuit current density, the open circuit voltage of intense light concentration solar cell under magnetic field.

These results showed that with the increase of magnetic field, the fill factor and the open circuit voltage increase, while the short circuit current density and the maximum electric power decrease. The increase of fill factor with magnetic field increase is the consequence of the strength of Lorentz which leads to carrier storage near the solar cell's junction [5]. The carrier storage at the junction is the consequence of the open circuit voltage increase and leads also to increase carrier's recombination in the base and then series resistance $R_{s}$ increase [11]. This situation leads none the less to a reduction of the quantity of carrier that crosses the junction to participate to the photocurrent, but also to an increase of the shunt resistance $R_{s h}$ through the solar cell's intrinsic junction recombination velocity increase [9].

\section{Magnetic field effect on the external optimal charge load}

The curves in Figure 3 show another method of electrical parameters (maximum electric power $P_{e l \max }$, maximum power point photovoltage $V_{\max }$ and photocurrent density $J_{\max }$ and optimal load resistance $R_{o p t}$ ) determination different of the one used by Zerbo et al. [10].

For the determination of the electrical parameters, we plotted in the same axes system (Figure 3 ), the J-V and equipower curves for a given magnetic field intensity.

The expression of the function that led to the equipower curves is given by Equation 15:

$$
E P=\frac{P_{\text {elmax }}}{V}
$$

The ideal operating point is the one corresponding to the intersection of the equipower curve and the $\mathrm{J}-\mathrm{V}$ characteristic. At this point, we determined the optimal external load resistance $R_{\text {opt }}$ of the solar cell,

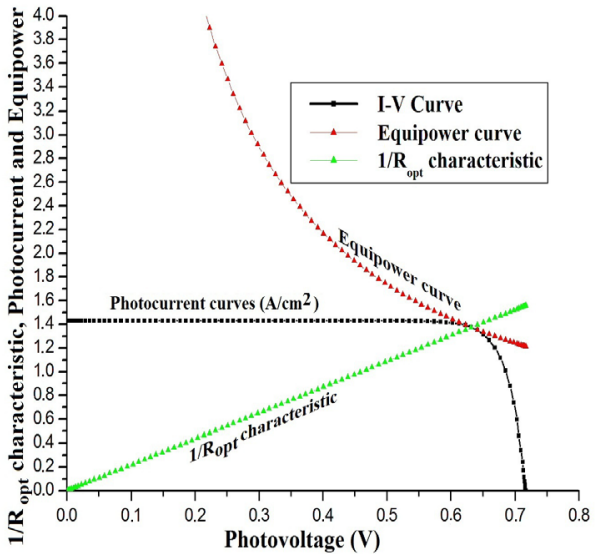

Fig. 3. Light concentration solar cell's electrical parameters determination using $\mathrm{J}-\mathrm{V}$ and equipower curves

whose inverse $\left(1 / R_{\text {opt }}\right)$ corresponds to the slope of the straight line passing by the $\mathrm{J}-\mathrm{V}$ curve origin and joining the maximum power point. The expression of the characteristic of the optimal external load resistance is given by Equation 16:

$$
C R_{\text {opt }}=\frac{J_{\max }}{V_{\max }} \cdot V
$$

In Table 3 the values of the maximum electric power, the maximum power point photovoltage $\left(\mathrm{V}_{\max }\right)$ and photocurrent density $\left(\mathrm{J}_{\text {max }}\right)$ and the optimal load resistance $\mathrm{R}_{\text {opt }}$ of intense light concentration solar cell for various magnetic field intensity are given.

We observed in this table that, with the increase of magnetic field, the maximum power point photovoltage $\left(\mathrm{V}_{\max }\right)$ and the optimal load resistance increase while the maximum power point photocurrent density $\left(\mathrm{J}_{\max }\right)$ decrease. The optimal load resistance increase with magnetic field increase is not benefitial for the solar and it is the consequence of the carrier storage near the junction with the magnetic field increase. Indeed, the carriers storage at the junction leads to the open circuit voltage increase and to the decrease of short circuit pho-

Table 3. Magnetic field effects on maximum electric power, maximum power point photovoltage $\left(V_{\max }\right)$ and pho-

\begin{tabular}{|c|c|c|c|c|c|}
\hline $\begin{array}{l}\text { Magnetic field } \\
\text { intensity } \\
B(m T)\end{array}$ & $\begin{array}{c}\text { Maximum } \\
\text { electric power } \\
\mathrm{P}_{\text {el max }}\left(\mathrm{mW} / \mathrm{cm}^{2}\right)\end{array}$ & $\begin{array}{l}\text { Values of } V_{\text {max }} \\
(\mathrm{mV})\end{array}$ & $\begin{array}{l}\text { Values of } \mathrm{J}_{\max } \\
\qquad\left(\mathrm{mA} / \mathrm{cm}^{2}\right)\end{array}$ & $\begin{array}{c}\text { Slopes of } \mathrm{R}_{\mathrm{opt}} \text { charac- } \\
\text { teristics } \\
\left(\Omega^{-1} \cdot \mathrm{cm}^{-2}\right)\end{array}$ & $\begin{array}{l}\text { Values of } R_{\mathrm{opt}} \\
\quad\left(\Omega \cdot \mathrm{cm}^{2}\right)\end{array}$ \\
\hline 0 & 870 & 632 & 1376 & 2.177 & 0.459 \\
\hline 0.5 & 851 & 641 & 1327 & 2.070 & 0.483 \\
\hline 1.5 & 781 & 649 & 1205 & 1.857 & 0.539 \\
\hline 3 & 703 & 666 & 1056 & 1.586 & 0.631 \\
\hline 5 & 635 & 673 & 943 & 1.401 & 0.714 \\
\hline
\end{tabular}
tocurrent density $\left(J_{\max }\right)$, and optimal load resistance 
tocurrent density and then to the reduction of the photocurrent density that crosses the external load. As the external load is in parallel with the solar cell, an increase of the open circuit voltage with a decrease of the photocurrent density that crosses the external load leads inevitably to the external load resistance increase.

\section{CONCLUSION}

This study showed that with the increase of magnetic field, the maximum electric power produced by the solar decrease and moves to the small values of junction dynamic velocity and this behavior means a reduction of the quantity of carriers which cross the junction to participate to the photocurrent with magnetic field increase. We have also put in evidence that the maximum electric power leads to the solar cell external load and its conversion efficiency decreases with the increase of external magnetic field. This result confirmed the reduction of the quantity of carriers that cross the junction with magnetic field increase.

The magnetic field effect on the solar cell also led to the carrier storage near the solar cell's junction and had as consequence the increase of the fill factor and the open circuit voltage. We noted that the optimal load resistance increase with the magnetic field increase. That means for a given load resistance, the increase of magnetic field induced a decrease of the maximum electric power and the conversion efficiency, and therefore the magnetic field causes a deterioration of the solar cell efficiency.

\section{REFERENCES}

1. Betser Y., Ritter D., Bahir G., Cohen S. and Sperling J. Measurement of the minority carrier mobility in the base of heterojunction bipolar transistor using magneto-transport method. Journal of Applied Physics Letters, 67 (13), 1995, 1883-1884.

2. Erel S. The effect of electric and magnetic fields on the operation of a photovoltaic cell. Solar Energy Materials \& Solar Cells, 71, 2002, 273-280..

3. Vardanyan R. R., Kerst U., Wawer P. and Wagemann H. Method for measurement of all recombination parameters in the base region of solar cells. Proc of $2^{\text {nd }}$ World Conference and Exhibition on Photovoltaic Solar Energy Conversion. Vienna, Austria, 1998, 191-193.

4. Zouma B., Maiga A. S., Dieng M. and Zougmoré F. 3D approach of spectral response for a bifacial silicon solar cell under a constant magnetic field. Global journal of pure and applied sciences, 15(1), 2009, 117-124.

5. Zoungrana M., Zerbo I., Seré A. D., Zouma B. and Zougmoré F. 3D Study of Bifacial Silicon Solar Cell Under Intense Light Concentration and Under External Constant Magnetic Field: Effect of magnetic field on carriers mobility and carriers density. Global Journal of Engineering Research, 10 (1-2), 2011, 113-124.

6. Zoungrana M., Zerbo I., Ouedraogo F., Zouma B. and Zougmoré F. 3D modelling of magnetic field and ligth concentration effects on a bifacial silicon solar cell illuminated by its rear side. IOP Conference Series: Materials Science and Engineering, 29, 2012, 012020.

7. Zerbo I., Zoungrana M., Seré A. D. and Zougmoré F. Silicon solar cell under electromagnetic wave in steady state: effect of the telecommunication source's power of radiation. IOP Conference Series: Materials Science and Engineering, 29, 2012, 012019.

8. Erel S. Comparing the Behaviors of some typical Solar Cells Under External Effects. TEKNOLOJ, 11 (3), 2008, 233-237.

9. Zerbo I., Zoungrana M., Sourabié I., Ouedraogo A., Zouma B. and Bathiebo D. J. External magnetic field effect on bifacial silicon solar cell's electric power and conversion efficiency. Turkish Journal of Physics, 39, 2015, 288- 294.

10. Zerbo I., Zoungrana M., Sourabié I., Ouedraogo A., Zouma B. and Bathiebo D. J. External magnetic field effect on bifacial silicon solar cell's electrical parameters. Energy and Power Engineering, 8, 2016, 146-151.

11. Sané M. and Barro F. I. Effect of both magnetic field and doping density on series and shunt resistances under frequency. Indian Journal of Pure and Applied Physics, 53, 2015, 590-595.

12. Pelanchon F., Sudre C. and Moreau Y. Solar cells under intense light concentration: numerical and analytical approaches. Proc of $11^{\text {th }}$ European Photovoltaic Solar Energy Conference. Montreux, France, 1992, 265-267.

13. Mohammad S.N. An Alternative Method of the Performance Analysis of Silicon Solar Cells. Journal of Applied Physics, 61(2), 1987, 767-772.

14. Dugas J. 3D modelling of a reverse cell made with improved multicrystalline silicon wafers. Solar Energy Materials and Solar cells 32, 1994, 71-88.

15. Ba B., Kane M. and Sarr J. Modeling recombination current in polysilicon solar cell grain boundaries.Solar Energy Materials \& Solar Cells 80, 2003, 143-154.

16. Equer B. Energie Solaire Photovoltaique: Physique et technologie de la conversion photovoltaique. UNESCO, 1991. 